\title{
EFEITO RESIDUAL DE HERBICIDAS AUXÍNICOS EM SOJA
}

\section{RESIDUAL EFFECT OF AUXINIC HERBICIDES ON SOY}

Paulo César Timossi ${ }^{\mathrm{a}}$, Angela Marques Gazarini ${ }^{\mathrm{b}}$, Beatriz Branco Tiago Queiroz ${ }^{\mathrm{b}}$, Dênio Celestino Gonçalves ${ }^{\mathrm{b} *}$, Dieimisson Paulo Almeida ${ }^{\mathrm{c}}$, Raimunda Orineide Barros de Araújo ${ }^{b}$, Itamar Rosa Texeira ${ }^{d}$

${ }^{a}$ Unidade Acadêmica de Ciências Agrárias, Universidade Federal de Jataí, Goiás, Brasil. 'bepartamento de Agronomia, Universidade Federal de Jataí, Goiás, Brasil. 'Departamento de Agricultura, Instituto de Ciência e Tecnologia COMIGO, Goiás, Brasil. ${ }^{\mathrm{d} U n i d a d e}$ Acadêmica de Ciências Agrárias, Universidade Estadual de Goiás, Goiás, Brasil

*Autor correspondente: dcgoncalves@gmail.com.

\section{INFORMAÇÕES DO ARTIGO}

\section{Histórico do artigo:}

Recebido: 13 Novembro 2019.

Aceito: 02 Outubro 2020.

Publicado: 10 Dezembro 2020.

\section{Palavras-chave/Keywords:}

2,4-D/ 2.4-D.

Carryover/ Carryover. Germinação/ Germination. Glycine $\max$ L./ Glycine $\max$ L.. Picloram/ Picloram.

Direito Autoral: Este é um artigo de acesso aberto distribuído sob os termos da Licença Creative Commons, que permite uso, distribuição e reprodução irrestritos em qualquer meio, desde que $\mathrm{o}$ autor $\mathrm{e}$ a fonte originais sejam creditados.

\section{Citação deste artigo:}

TIMOSSI, P. C.; GAZARINI, A. M.; QUEIROZ, B. B. T.; GONÇALVES, D. C.; ALMEIDA, D. P.; ARAÚJO, R. O. B.; TEXEIRA, I. R. Efeito residual de herbicidas auxínicos em soja. Revista Brasileira de Herbicidas, v. 19, n. 3. 2020.

\begin{abstract}
RESUMO
O controle das plantas daninhas em pastagens é indispensável para melhoria dos índices de produtividade da atividade agropecuária e a utilização correta e consciente dos herbicidas é muito importante para reduzir os problemas ocasionados pelo efeito residual em culturas subsequentes. Portanto, avaliou-se com este estudo o efeito residual dos herbicidas auxínicos 2,4-D, picloram e 2,4-D + picloram no desenvolvimento inicial de plântulas de soja. O trabalho foi conduzido em casa de vegetação no delineamento inteiramente casualizado, em esquema fatorial $7 \times 3$, com quatro repetições. $\mathrm{O}$ primeiro fator foi composto pelas porcentagens das doses recomendadas de herbicidas $(100 \%, 50 \%, 25 \%$, $12,50 \%, 6,25 \%, 3,12 \%$ e $0,00 \%)$ na qual a maior dose $(100 \%)$ foi equivalente a $2 \mathrm{~L} \mathrm{ha}^{-1}$. O segundo fator foi composto pelos herbicidas: $2,4-\mathrm{D}$, picloram $+2,4-\mathrm{D}$ e picloram. Foram avaliados o número de plantas emergidas para cada tratamento aos 10 DAS, altura de plantas e acúmulo de massa fresca e seca aos 40 DAS. O herbicida picloram afeta negativamente as variáveis número e altura de plantas a partir da dose $3,12 \%$ e massa fresca e seca a partir da dose $6,25 \%$ e o herbicida picloram $+2,4-\mathrm{D}$ afeta negativamente as variáveis número de plantas a partir da dose $3,12 \%$, altura de plantas a partir da dose $6,25 \%$ e massa fresca e seca a partir da dose $12,5 \%$. A soja demonstrou alta sensibilidade aos resíduos de picloram no solo. As doses $25 \%$ e $50 \%$ respectivamente, dos herbicidas picloram + 2,4-D e picloram, limitaram a emergência das plântulas e a dose $100 \%$ impediu a germinação das sementes de soja. Não foi observado efeito residual para o herbicida 2,4-D em plântulas de soja em quaisquer das doses estudadas.
\end{abstract}




\section{Introdução}

No Brasil existem cerca de 200 milhões de hectares de pastagens nativas ou implantadas, das quais se estima que aproximadamente 130 milhões apresentam baixo ou nenhum investimento (EMBRAPA, 2019). A falta de manutenção da fertilidade do solo, o excesso de lotação e ausência de controle de insetos-praga, doenças e plantas daninhas tornam a pastagem degradada, promovendo inúmeros prejuízos (PAULINO et al., 2012).

O controle das plantas daninhas é um dos fatores indispensáveis para melhoria dos índices de produtividade da atividade agropecuária. $\mathrm{O}$ controle pode ser realizado de diversas formas, entre eles o método químico é o mais utilizado devido seu baixo custo e eficácia (PELLEGRINI et al., 2010; RODRIGUES; ALMEIDA, 2011).

Os herbicidas do grupo das auxinas sintéticas têm sido os mais usados no controle de plantas daninhas eudicotiledôneas em forrageiras devido à seletividade. As principais moléculas usadas têm sido o 2,4-D e o picloram, que compõem a maioria das formulações comerciais recomendadas para pastagens. Alguns produtos apresentam característica de persistir no solo, pois têm de promover efeito de controle das plantas daninhas por longos períodos (SILVA et al., 2011; BRAGA et al., 2013).

O 2,4-D apresenta persistência, de curta a média, sendo que a atividade residual não excede a quatro semanas em solos argilosos e clima quente (SILVA;VARGAS; FERREIRA, 2007), enquanto que o picloran apresenta uma longa persistência no solo, podendo ser encontrado em até 3 anos após a aplicação de forma pulverizada (SILVA, 2011). A persistência de um herbicida no solo aumenta a probabilidade de ocorrência de efeito residual (MANCUSO; NEGRISOLI; PERIM, 2011). De acordo com Timossi et al. (2013), os herbicidas que apresentam atividade residual no solo em período superior ao ciclo de vida de uma cultura, podem interferir em cultivos sucessores. Nessa situação, esse efeito é denominado de Carryover (ALONSO; OLIVEIRA JÚNIOR; CONSTANTIN, 2013).

A utilização correta e consciente dos herbicidas é muito importante, pois o setor agrícola tem sido questionado e julgado do ponto de vista ambiental. Buscando-se encontrar formas de reduzir o risco do impacto ambiental que o efeito residual de herbicida possa vir a causar, além de minimizar problemas de fitointoxicação e perdas em culturas subsequentes, diversos estudos têm sido realizados (SILVA et al., 2011; SANTOS et al., 2013; FRANCESCHI et al., 2017), especialmente para compreender o comportamento desses produtos no solo.

Em estudos sobre atividade de moléculas herbicidas nos solos, pesquisadores têm utilizado bioensaios, que aliam baixo custo a bom resultado prático. Essa técnica consiste em utilizar plantas sensíveis aos produtos testados, fazendo com que os resíduos dos herbicidas ou soluções presentes no solo possam ser evidenciados por meio da alteração das características agronômicas da planta-teste (MELO et al., 2010; MANCUSO; NEGRISOLI; PERIM, 2011).

A soja (Glycine max) por ser uma eudicotiledônea, apresenta alta suscetibilidade à aplicação de herbicidas auxínicos, tornando-se uma opção de espécie bioindicadora. Além disso, a cultura tem alternado áreas de cultivos com pastagens anuais. Sendo assim, estudos dessa natureza constituem uma importante e relevante contribuição para o sistema de manejo em que a soja é cultura subsequente (BALBINOT JÚNIOR; VEIGA, 2010; FRANCESCHI et al, 2015). Neste contexto, objetivou-se com este estudo avaliar o efeito residual dos herbicidas 2,4-D, picloram e 2,4-D + picloram no desenvolvimento inicial de plântulas de soja.

\section{Material e Métodos}

O presente trabalho foi conduzido em casa de vegetação da Universidade Federal de Jataí, Campus Jatobá, Goiás. A área onde o experimento foi implantado possui 685 metros de altitude nas seguintes coordenadas geográficas $17^{\circ} 55^{\prime} 25^{\prime}$ 'S e $51^{\circ} 42^{\prime} 39^{\prime}$ 'O. O delineamento experimental adotado foi o inteiramente casualizado, em esquema fatorial $7 \times 3$, com quatro repetições.

$\mathrm{O}$ primeiro fator foi composto pelas porcentagens decrescentes das doses recomendadas de herbicidas (100\%, $50 \%, 25 \%, 12,5 \%, 6,25 \%, 3,12 \%$ e $0,00 \%$ ) sendo a maior dose $(100 \%)$ equivalente a $2 \mathrm{~L} \mathrm{ha}^{-1}$. O segundo fator foi composto pelos herbicidas: 2,4-D, sal dimetilamina (DMA 806 BR SL, 806 g i.a.ha ${ }^{-1}$, SL, Dow AgroSciences), picloram, sal de trietanolamina $+2,4-\mathrm{D}$, sal de trietanolamina (Tordon, 103,6 e 402 g i.a.ha ${ }^{-1}$, SL, Dow AgroSciences) e picloram, sal de trietanolamina (Padron, 388,3 g i.a.ha ${ }^{-1}$, SL, Dow AgroSciences). As doses de picloram e 2,4-D foram baseadas na mistura comercial do herbicida Tordon, adequando-a para o produto DMA (2,4-D) e Padron (picloram) no intuito de manter a mesma proporção de dosagem em g i.a.ha ${ }^{-1}$ (Tabela 1).

Tabela 1. Descrição dos tratamentos experimentais, com as respectivas doses em g i. a. ha ${ }^{-1}$.

\begin{tabular}{cccc}
\hline & \multicolumn{2}{c}{ Dosagem de Herbicidas } & \\
\hline $\begin{array}{c}\text { Tratamentos } \\
(\% \text { da dose })\end{array}$ & Picloram $+2,4-\mathrm{D}$ & Picloram & $2,4-\mathrm{D}$ \\
\hline $0,00 \%$ & $0,00^{1}$ & 0,00 & 0,00 \\
$3,12 \%$ & $4,00+15,00$ & 4,00 & 15,00 \\
$6,25 \%$ & $8,00+30,00$ & 8,00 & 30,00 \\
$12,5 \%$ & $16,00+60,00$ & 16,00 & 60,00 \\
$25 \%$ & $32,00+120,00$ & 32,00 & 120,00 \\
$50 \%$ & $64,00+240,00$ & 64,00 & 240,00 \\
$100 \%$ & $128,00+480,00$ & 128,00 & 480,00 \\
\hline
\end{tabular}

${ }^{1}$ Dados expressos em gramas de ingrediente ativo por hectare. 
Cada unidade experimental foi constituída por um vaso de plástico com capacidade de $3 \mathrm{dm}^{-3}$ preenchidos com solo de textura argilosa, classificado como Latossolo Vermelho distroférrico. No preparo do solo para preenchimento dos vasos, foi acrescentado os fertilizantes superfosfato simples $\left(\mathrm{P}_{2} \mathrm{O}_{5}\right)$ e cloreto de potássio $(\mathrm{KCl})$ e corretivos (calcário e gesso) de acordo com a necessidade determinada na análise química de solo (Tabela 2).

Tabela 2. Composição química e textural do solo utilizado na pesquisa.

\begin{tabular}{|c|c|c|c|c|c|c|c|c|c|c|}
\hline \multicolumn{11}{|c|}{ Análise Textural (\%) } \\
\hline Areia & & Silte & Argila & \multirow{2}{*}{\multicolumn{7}{|c|}{$\begin{array}{c}\text { Classificação Textural } \\
\text { Argilosa }\end{array}$}} \\
\hline 29,74 & & 23,19 & 47,07 & & & & & & & \\
\hline \multicolumn{11}{|c|}{ Análise química } \\
\hline $\begin{array}{c}\mathrm{pH} \\
\left(\mathrm{H}_{2} \mathrm{O}\right)\end{array}$ & $\begin{array}{c}\mathrm{P} \\
\left(\mathrm{mg} / \mathrm{dm}^{3}\right)\end{array}$ & $\mathrm{K}$ & $\mathrm{Al}$ & & $\begin{array}{l}\mathrm{Mg} \\
\left.\mathrm{m}^{3}\right)\end{array}$ & $\mathrm{H}+\mathrm{Al}$ & CTC & $\mathrm{V}$ & $\mathrm{m}$ & $\begin{array}{l}\mathrm{MO} \\
\mathrm{g} / \mathrm{kg}\end{array}$ \\
\hline 5,06 & 10,45 & 0,34 & 0,18 & 2,57 & 1,14 & 4,46 & 8,51 & 47,62 & 4,25 & 22,54 \\
\hline
\end{tabular}

Após o preenchimento dos vasos com o solo foi realizado a aplicação dos herbicidas com pulverizador de pesquisa pressurizado por $\mathrm{CO}_{2}$, com pressão constante de $210 \mathrm{kPa}$, munido de um bico com ponta de jato dirigido do tipo DG 9502 EVS e ajustado para um volume de aplicação de $200 \mathrm{~L} \mathrm{ha}^{-1}$. No momento da aplicação dos tratamentos, a temperatura média do ar foi $28,5{ }^{\circ} \mathrm{C}$, umidade relativa (UR\%) de 49,0\%, temperatura do solo de $21,1{ }^{\circ} \mathrm{C}$ e a velocidade do vento de $3 \mathrm{~km} \mathrm{~h}^{-1}$.

Durante 10 dias após a aplicação dos herbicidas foi simulado uma precipitação acumulada de $70 \mathrm{~mm}$, para melhor distribuição do herbicida ao solo. Em seguida (11 dias após aplicação), foi realizada a semeadura distribuindose dez sementes de soja por vaso na profundidade de até 3 $\mathrm{cm}$. A reposição de água foi feita diariamente de acordo com a necessidade da cultura. A cultivar de soja utilizada como planta biodincadora foi a NS 7300 IPRO.

A avaliação do número de plântulas emergidas para cada tratamento foi realizada aos 10 dias após a semeadura (DAS) contando-se o número de plantas emergidas. Ainda, no intuito de verificar possíveis sintomas de fitointoxicação nas plantas, foi determinada a altura de plantas aos 40 DAS com auxílio de régua graduada em centímetros. Ao final do experimento (40 DAS) também foi determinada o acúmulo de massa fresca e seca. Para massa fresca, as plantas foram cortadas rente ao solo e pesadas em balança analítica, e em seguida, foram acondicionadas em câmara com circulação de ar regulada a $60{ }^{\circ} \mathrm{C}$ durante três dias $(72 \mathrm{~h})$. Após esse período, as plantas foram retiradas e pesadas novamente para determinação de massa seca.

Para a interpretação dos resultados, os dados obtidos foram submetidos à análise de variância e as médias comparadas pelo Teste de Tukey, adotando-se o nível de 5\% de significância. O software usado para as análises foi o AgroEstat ${ }^{\circledR}$ (BARBOSA; MALDONADO JUNIOR, 2010).

\section{Resultados e Discussão}

$\mathrm{Na}$ Tabela 3 são apresentados os resultados da análise de variância para o número de plantas de soja emergidas aos 10 dias após a semeadura (DAS). Aos 10 DAS houve interação significativa entre os fatores (doses $\mathrm{x}$ herbicidas) avaliados.

Tabela 3. Resumo da análise de variância com os valores de F para número de plantas de soja (Glycine max) determinadas aos 10 dias após a semeadura (DAS).

\begin{tabular}{cc}
\hline Fatores & 10 DAS \\
\hline F colunas (doses) & $74,94 * *$ \\
F linhas (herbicidas) & $45,34^{* *}$ \\
F1x F2 & $9,72 * *$ \\
\hline
\end{tabular}

**significativo ao nível de $1 \%$ de probabilidade.

Na comparação das médias do número de plântulas emergidas de soja aos 10 DAS (Tabela 4), verificou-se que houve diferença significativa entre os herbicidas. Na dose de $3,12 \%$, o picloram $+2,4-\mathrm{D}$ causou maior redução na emergência de plântulas quando comparado a aplicação de 2,4-D, porém não houve diferença estatística para o picloram.

$\mathrm{Na}$ dose de $6,25 \%$, o picloram $+2,4-\mathrm{D}$ causou maior redução na emergência de plântulas $(4,00)$ em comparação aos demais herbicidas (Tabela 4). Na dose de 12,5\%, a menor emergência de plântulas foi observada para os tratamentos com picloram $+2,4-\mathrm{D}$ e picloram, com emergência de 4,00 e 5,00 plântulas por vaso, respectivamente. $\mathrm{Na}$ dose de $25 \%$, o herbicida picloram causou a menor emergência de plantas $(2,00)$ e nas doses $50 \%$ e $100 \%$ os herbicidas picloram e picloram $+2,4-\mathrm{D}$ impediram a germinação das plantas $(0,00)$ (Tabela 4$)$. 
P. C. TIMOSSI et al

Tabela 4. Desdobramento da interação para médias de número de plantas de soja determinadas aos 10 dias após a semeadura.

\begin{tabular}{cccc}
\hline \multirow{2}{*}{ Doses } & \multicolumn{3}{c}{$10 \mathrm{DAS}$} \\
\cline { 2 - 4 } & $2,4-\mathrm{D}$ & Picloram $+2,4-\mathrm{D}$ & Picloram \\
\hline $0,00 \%$ & $8,00 \mathrm{a} \mathrm{A}^{1}$ & $8,75 \mathrm{a} \mathrm{A}$ & $7,75 \mathrm{a} \mathrm{A}$ \\
$3,12 \%$ & $7,75 \mathrm{a} \mathrm{A}$ & $5,50 \mathrm{~b} \mathrm{~B}$ & $7,50 \mathrm{a} \mathrm{AB}$ \\
$6,25 \%$ & $7,00 \mathrm{a} \mathrm{A}$ & $4,00 \mathrm{~b} \mathrm{~B}$ & $7,75 \mathrm{a} \mathrm{A}$ \\
$12,5 \%$ & $7,75 \mathrm{a} \mathrm{A}$ & $4,00 \mathrm{~b} \mathrm{~B}$ & $5,00 \mathrm{~b} \mathrm{~B}$ \\
$25 \%$ & $7,75 \mathrm{a} \mathrm{A}$ & $4,00 \mathrm{~b} \mathrm{~B}$ & $2,00 \mathrm{c} \mathrm{C}$ \\
$50 \%$ & $6,25 \mathrm{a} \mathrm{A}$ & $0,25 \mathrm{~b} \mathrm{C}$ & $0,25 \mathrm{~b} \mathrm{C}$ \\
$100 \%$ & $6,75 \mathrm{a} \mathrm{A}$ & $0,00 \mathrm{~b} \mathrm{C}$ & $0,00 \mathrm{~b} \mathrm{C}$ \\
\hline DMS colunas & & 1,98 & \\
DMS linhas & & 2,51 & \\
CV\% & & 22,65 & \\
\hline
\end{tabular}

${ }^{1}$ Médias seguidas pela mesma letra minúscula na linha ou por letras maiúsculas na coluna não diferem estatisticamente entre si com $\mathrm{p}<0,01$.

Analisando as doses dentro de cada herbicida nota-se que o herbicida picloram $+2,4-\mathrm{D}$, da menor dose até a maior dose apresentou efeito residual para a cultura. Nas doses $3,12 \%, 6,25 \%, 12,5 \%$ e $25 \%$ este herbicida afetou o desenvolvimento inicial das plantas de soja, culminando em uma densidade média entre 5,5 e 4,0 plantas por unidade experimental, enquanto nas doses $50 \%$ e $100 \%$, limitou as plantas de soja a emergirem.

$\mathrm{O}$ herbicida picloram apresentou efeito residual a partir da dose $12,5 \%$ até a dose $100 \%$. A dose $12,5 \%$ afetou o desenvolvimento inicial das plantas de soja, levando a densidade média de 5,0 plantas, enquanto as doses $25 \%$, $50 \%$ e $100 \%$, limitaram as plantas de soja a emergirem. Já o 2,4-D não apresentou efeito residual. Este resultado pode ser atribuído a simulação de precipitação que foi realizada, e pelo fato de o 2,4-D possuir um tempo de meia-vida considerado relativamente baixo no solo, que levou a remoção física do mesmo através da lixiviação (BRITO et al., 2001; AMARANTE JUNIOR et al., 2002; BAKHTIARY; HIRVANI; SHARIATMADARI, 2013). Por serem menos eficientes em atravessar a cutícula e possuir maior solubilidade em água as aminas se tornam mais susceptíveis à formação de precipitados e menos resistentes à lavagem por chuvas ocorridas após a aplicação (NICE; JOHNSON; BAUMAN, 2004; ROMAN et al., 2005).

$\mathrm{O}$ picloram e o picloram $+2,4-\mathrm{D}$ apresentam em relação aos demais herbicidas registrados no Brasil, um dos maiores períodos de atividade residual em solos (RODRIGUES; ALMEIDA, 2005). Santos et al. (2006) observaram efeito residual de picloram e picloram $+2,4-\mathrm{D}$ no solo até 360 dias após a aplicação. Além disso o picloram apresenta Koc médio, de $16 \mathrm{~mL} \mathrm{~g}^{-1}$ de solo (SILVA;
FERREIRA; FERREIRA, 2005). Inoue et al. (2003), afirmam que, por apresentar longa persistência e baixo Koc, o picloram é considerado um herbicida com alto potencial de fitointoxicação.

$\mathrm{Na}$ Tabela 5 são apresentados os resultados da análise de variância de altura de plantas de soja aos 40 DAS. Houve interação significativa entre os fatores (doses $\mathrm{x}$ herbicidas) avaliados. Na comparação das médias de altura de plantas de soja aos 40 DAS (Tabela 6), verificou-se que houve diferença significativa entre os herbicidas. $\mathrm{O}$ picloram $+2,4$-D e o picloram causaram a maior redução na altura de plantas para todas as doses avaliadas quando comparados ao 2,4-D isolado (Tabela 6). Em relação as doses para cada herbicida, o 2,4-D não causou redução na altura das plantas de soja em nenhuma das doses avaliadas. $\mathrm{O}$ picloram + 2,4-D e o picloram causaram redução na altura das plantas a partir da dose de 3,12\%. A partir da dose de $25 \%$, os tratamentos com picloram $+2,4-\mathrm{D}$ e picloram causaram a morte das plantas (Tabela 6).

Resultados semelhantes foram encontrados por Carmo et al. (2008), avaliando a altura de plantas de soja cultivada em solo tratado com picloram, demonstrando que estas variáveis foram reduzidas aos 15 e 40 dias após a emergência (DAE), indicando que a soja é muito sensível à presença deste herbicida no solo. A não redução na altura das plantas de soja pelo 2,4-D, pode ter ocorrido devido a rápida lixiviação e degradação do herbicida no solo. Fagundes (2018) constatou crescimento expressivo de plantas tratadas com 2,4-D com chuva simulada de $30 \mathrm{~mm}$, pois houve a solubilização do herbicida na água o que provocou a sua lixiviação.

Tabela 5. Resumo da análise de variância com os valores de F para altura de plantas de soja (Glycine max) determinadas aos 40 dias após a semeadura.

\begin{tabular}{cc}
\hline Fatores & 40 DAS \\
\hline F colunas (doses) & $319,22^{* *}$ \\
F linhas (herbicidas) & $81,16^{* *}$ \\
F1x F2 & $17,16^{* *}$ \\
\hline
\end{tabular}

\footnotetext{
**significativo ao nível de $1 \%$ de probabilidade.
} 
P. C. TIMOSSI et al

Tabela 6. Desdobramento da interação para médias de altura de plantas de soja determinadas aos 40 dias após a semeadura.

\begin{tabular}{|c|c|c|c|}
\hline \multirow{2}{*}{ Doses } & \multicolumn{3}{|c|}{40 DAS } \\
\hline & Picloram + 2,4-D & Picloram & $2,4-\mathrm{D}$ \\
\hline $0,00 \%$ & 18,33 a $\mathrm{BB}^{1}$ & 18,74 a $\mathrm{A}$ & 19,91 a $A$ \\
\hline $3,12 \%$ & 20,99 a A & 11,83 b B & $15,35 \mathrm{~b} B$ \\
\hline $6,25 \%$ & 16,41 a B & 7,02 b C & $8,70 \mathrm{~b} \mathrm{C}$ \\
\hline $12,5 \%$ & 18,99 a $\mathrm{AB}$ & 1,83 b D & $2,33 \mathrm{~b} \mathrm{D}$ \\
\hline $25 \%$ & 16,62 a $\mathrm{AB}$ & $0,00 \mathrm{~b} \mathrm{D}$ & $0,00 \mathrm{~b} D$ \\
\hline $50 \%$ & 19,29 a $\mathrm{AB}$ & $0,00 \mathrm{~b} \mathrm{D}$ & $0,00 \mathrm{~b} \mathrm{D}$ \\
\hline $100 \%$ & $16,95 \mathrm{a} A \mathrm{~B}$ & $0.00 \mathrm{~b} \mathrm{D}$ & $0,00 \mathrm{~b} \mathrm{D}$ \\
\hline DMS colunas & \multicolumn{3}{|c|}{3,52} \\
\hline DMS linhas & \multicolumn{3}{|c|}{4,47} \\
\hline $\mathrm{CV} \%$ & \multicolumn{3}{|c|}{20,43} \\
\hline
\end{tabular}

${ }^{1}$ Médias seguidas pela mesma letra minúscula na linha ou por letras maiúsculas na coluna não diferem estatisticamente entre si com $\mathrm{p}<0,01$.

$\mathrm{Na}$ Tabela 7 são apresentados os resultados da análise de variância de massa fresca e seca de plantas de soja determinadas aos $40 \mathrm{DAS}$, respectivamente. Para massa fresca e seca houve interação significativa entre os fatores (doses x herbicidas) avaliados. Na comparação das médias de massa fresca e seca de plantas de soja aos 40 DAS (Tabela 8), verificou-se que houve diferença significativa entre os herbicidas.

Tabela 7. Resumo da análise de variância com os valores de F para massa fresca e seca de plantas de soja (Glycine max) determinadas aos 40 dias após a semeadura.

\begin{tabular}{ccc}
\hline Fatores & Massa Fresca & Massa Seca \\
F colunas (doses) & $123,67 * *$ & $49,25 * *$ \\
F linhas (herbicidas) & $37,09 * *$ & $28,22 * *$ \\
F1x F2 & $7,16^{* *}$ & $5,60 * *$ \\
\hline
\end{tabular}

**significativo ao nível de $1 \%$ de probabilidade.

Tabela 8. Desdobramento da interação para médias de massa fresca e seca de plantas de soja determinadas aos 40 dias após a semeadura.

\begin{tabular}{|c|c|c|c|c|c|c|}
\hline \multirow[t]{2}{*}{ Doses } & \multicolumn{3}{|c|}{ Massa Fresca (g) } & \multicolumn{3}{|c|}{ Massa Seca (g) } \\
\hline & $2,4-\mathrm{D}$ & Picloram + 2,4-D & Picloram & $2,4-\mathrm{D}$ & Picloram + 2,4-D & Picloram \\
\hline $0,00 \%$ & $4,00 \mathrm{a} \mathrm{A}^{1}$ & 3,76 a $\mathrm{A}$ & 4,01 a $A$ & 1,00 a B & 1,09 a A & 1,15 a A \\
\hline $3,12 \%$ & 4,11 a $\mathrm{A}$ & 3,91 a $\mathrm{A}$ & $2,09 \mathrm{~b} \mathrm{~B}$ & 1,17 a $\mathrm{AB}$ & 1,22 a $\mathrm{A}$ & 0,80 a $\mathrm{AB}$ \\
\hline $6,25 \%$ & 3,75 a $A$ & $2,03 \mathrm{~b} \mathrm{~B}$ & 1,92 b B & 1,63 a $\mathrm{A}$ & 1,66 a $\mathrm{A}$ & $0,69 \mathrm{~b} \mathrm{AB}$ \\
\hline $12,5 \%$ & 3,46 a $A$ & $0,89 \mathrm{~b} \mathrm{BC}$ & $0,36 \mathrm{~b} \mathrm{C}$ & 0,99 a B & $0,42 \mathrm{~b}$ B & $0,29 \mathrm{~b} \mathrm{BC}$ \\
\hline $25 \%$ & 3,53 a $A$ & $0,00 \mathrm{~b} \mathrm{C}$ & $0,00 \mathrm{~b} \mathrm{C}$ & 1,03 a $\mathrm{B}$ & $0,00 \mathrm{~b} B$ & $0,00 \mathrm{~b} \mathrm{C}$ \\
\hline $50 \%$ & 3,58 a $A$ & $0,00 \mathrm{~b} \mathrm{C}$ & $0,00 \mathrm{~b} \mathrm{C}$ & $1,04 \mathrm{a} \mathrm{AB}$ & $0,00 \mathrm{~b} B$ & $0,00 \mathrm{~b} \mathrm{C}$ \\
\hline $100 \%$ & 3,59 a A & $0,00 \mathrm{~b} \mathrm{C}$ & $0,00 \mathrm{~b} \mathrm{C}$ & 1,01 a B & $0,00 \mathrm{~b} B$ & $0,00 \mathrm{~b} \mathrm{C}$ \\
\hline DMS colunas & & 1,10 & & & 0,46 & \\
\hline DMS linhas & & 1,39 & & & 0,59 & \\
\hline CV\% & & 34,07 & & & 37,88 & \\
\hline
\end{tabular}

${ }^{1}$ Médias seguidas pela mesma letra minúscula na linha ou por letras maiúsculas na coluna não diferem estatisticamente entre si $\operatorname{com} \mathrm{p}<0,01$.

Analisando as doses dentro de cada produto para massa fresca e seca o herbicida 2,4-D apresentou maiores médias de massa fresca $(4,00,4,11,3,75,3,46,3,53,3,58 \mathrm{e}$ $3,59 \mathrm{~g})$ respectivamente para as doses $0,00,3,12 \%, 6,25$, $12,5 \%, 25 \%, \quad 50 \%$ e $100 \%$. Porém, houve diferença significativa para massa seca, com o melhor valor para a dose $6,25 \%(1,63 \mathrm{~g})$.

Dias et al. (2012), avaliando lixiviação de 2,4-D, observaram um incremento da massa seca de soja devido a movimentação do herbicida por lixiviação. A chuva pode ter proporcionado uma uniforme distribuição do herbicida refletindo no crescimento das plantas, já que o 2,4-D atua como regulador de crescimento. Portanto, em pequenas quantidades e atuando como uma auxina, o herbicida é insuficiente para provocar o decréscimo da biomassa das plantas (SILVA, 2017).

O herbicida picloram apresentou redução dos valores a partir da dose $6,25 \%(1,92,0,36,0,00,0,00$ e $0,00 \mathrm{~g})$ de 
massa fresca e $(0,69,0,29,0,00,0,00$ e $0,00 \mathrm{~g})$ de massa seca. Enquanto que o herbicida picloram $+2,4-\mathrm{D}$ apresentou redução a partir da dose $12,5 \%$ para massa fresca $(0,89$, $0,00,0,00$ e $0,00 \mathrm{~g})$ e para massa seca $(0,42,0,00,0,00$ e $0,00 \mathrm{~g})$.

Assis et al. (2010), também encontraram redução nos valores de massa seca de soja com o aumento das doses do herbicida picloram. Esses resultados reforçam as considerações de Wax, Knuth e Slife (1969), sobre a alta sensibilidade da soja à presença do picloram, mesmo em quantidades extremamente baixas no solo, e intensifica o cuidado com o cultivo dessa planta em áreas com histórico de aplicações deste herbicida.

\section{Conclusões}

O herbicida picloram afeta negativamente $\mathrm{O}$ desenvolvimento da soja (NS 7300 IPRO) para as variáveis número e altura de plantas a partir da dose 3,12\% e massa fresca e seca a partir da dose $6,25 \%$. O herbicida picloram + 2,4-D afeta negativamente o desenvolvimento da soja para as variáveis número de plantas a partir da dose $3,12 \%$, altura de plantas a partir da dose $6,25 \%$ e massa fresca e seca a partir da dose $12,5 \%$. O 2,4-D não causa efeito residual na soja nas condições estudadas.

\section{Referências}

Alonso, D. G.; Oliveira Júnior, R. S.; Constantin, J. Potencial de carryover de herbicidas com atividade residual usados em manejo outonal. Buva: Fundamentos e recomendações para manejo. Curitiba: Omnipax, p. 91104, 2013.

Amarante Junior, O. P.; Santos, T. C. R.; Brito, N. M.; Ribeiro, M. L. Revisão das Propriedades, Usos e Legislação do Ácido 2,4-Diclorofenoxiacético (2,4-D). Cad. Pesq., São Luís, v.13, n.1, p.60-70, 2002.

Assis, R. L. D.; Procópio, S. D. O.; Carmo, M. L. D.; Pires, F. R.; Cargnelutti Filho, A.; Braz, G. B. Fitorremediação de solo contaminado com o herbicida picloram por plantas de capim pé de galinha gigante. Revista Brasileira de Engenharia Agrícola e Ambiental, v. 14, n. 11, p. 1131$1135,2010$.

Bakhtiary, S.; Hirvani, M.; Shariatmadari, H. Characterization and 2,4-D adsorption of sepiolite nanofibers modifies by $\mathrm{N}$-cetylpyridinium cátions. Microporous and Mesoporous Materials, v. 168, p. 30-36, 2013.

Balbinot Junior, A. A.; Veiga, M. Fundamentos do sistema integração lavoura-pecuária. Agropecuária Catarinense, v. 23, p.43-45, 2010.

Barbosa, J. C.; Maldonado Junior, W. Agrostat - Sistema para análises estatísticas de ensaios agronômicos. Versão 1.0. Jaboticabal: Departamento de Ciências Exatas, 2010 .

Braga, R. R.; Costa, S. S. D. da; Ferreira, E. A.; Santos, J. B. dos; Silva, D. V. Atividade microbiana de solos contaminados com picloram e cultivados com Urochloabrizantha. Enciclopédia Biosfera, Goiânia, v. 9, n. 17 , p. $302-314,2013$

Brito, N. M.; de Amarante Jr, O. P.; Abakerli, R.; Santos, T. C. R.; Ribeiro, M. L. Risco de contaminação de águas por pesticidas aplicados em plantações de eucaliptos e coqueiros: análise preliminar. Pesticidas: Revista de Ecotoxicologia e Meio Ambiente, Curitiba, v. 1l, jan./dez., p.93-104. 2001.

Carmo, M. L.; Procopio, S. O.; Pires, F. R.; Cargnelutti, A. F.; Braz, G. B. P.; Silva, W. F. P.; Barroso, A. L. L.; Silva, G. P.; Carmo, E. L.; Braz, A. J. B. P.; Assis, R. L. Influência do período de cultivo de Panicum maximum (cultivar Tanzânia) na fitorremediação de solo contaminado com picloram. Planta Daninha, v. 26, p. 315-322, 2008.

Dias, J. R. M.; Dubberstein, D.; Tavella, L. B., Ferreira, E.; Stachiw, R. Lixiviação de 2,4-D em solo de pastagem na Amazônia Ocidental. Agropecuária Científica no Semiárido, v. 7, n. 4, 2012.

Embrapa agrobiologia. Pastagens. Portal Embrapa, 2019. Disponível em <https://www.embrapa.br/agrobiologia/ pesquisa-e-desenvolvimento/pastagens $>$. Acesso em: $15 \mathrm{de}$ outubro de 2019.

Fagundes, A. S. Interferência da chuva no efeito residual do herbicida 2,4-D em latossolo vermelho do cerrado. Fundação Universidade Federal De Mato Grosso. Instituto De Ciências Agrárias E Tecnológicas. Curso De Engenharia Agrícola E Ambiental. Rondonópolis, 2018.

Franceschi, M.; Yamashita, O. M.; Arantes, S. A. D. C. M.: Andrade, S. P. Comportamento do 2, 4-D + picloram em Latossolo Vermelho Amarelo. Revista Brasileira de Herbicidas, v. 16, n. 3, p. 238-245, 2017.

Franceschi, M.; Ricardo, A. F.; Yamashita, O. M.; Lorenzon, J.; Carvalho M. A. C. Lixiviação do herbicida 2,4 -d + picloram em latossolo vermelho amarelo distrófico. Enciclopédia Biosfera, Centro Científico Conhecer Goiânia, v.11 n.22; p.2152, 2015.

Inoue, M. H.; Oliveira Jr, R. S.; Regitano, J. B.; Tormena, C. A.; Tornisielo, V. L.: Constantin, J. Critérios para avaliação do potencial de lixiviação dos herbicidas comercializados no estado do Paraná. Planta Daninha, v. 21, n. 2, p. 312-323, 2003.

Mancuso, M. A. C.; Negrisoli, E.; Perim, L. Efeito residual de herbicidas no solo ("Carryover"). Revista Brasileira de Herbicidas, v. 10, p. 151-164, 2011. 
Melo, C. A. D.; Medeiros, W. N.; Santos, L. D. T.; Ferreira, F. A.; Tiburcio, R. A. S.; Ferreira, L. R. Lixiviação de sulfentrazone, isoxaflutole e oxyfluorfen no perfil de três solos. Planta Daninha, Viçosa, v. 28, n. 2, p. 385-392, 2010 .

Nice, G.; Johnson, B.; Bauman, T. Amine or Ester, which is better?. Purdue Extension Weed Science. 2004.

Paulino, V. T.; Schumann, A. M.; Silva, S. C.; Rasquinho, N .M.; Santos, K. M. Impactos ambientais da exploração pecuária em sistemas intensivos de pastagem. Informe Agropecuário, Belo Horizonte, v. 33, n. 266, p. 17-24, 2012.

Pellegrini, L. G.; Nabinger, C.; Neumann, M.; Carvalho, P. C. F.; Crancio, L. A. Produção de forragem e dinâmica de uma pastagem natural submetida a diferentes métodos de controle de espécies indesejáveis e à adubação. Revista Brasileira de Zootecnia, v. 39, n. 11, p. 2380-2388, 2010.

Rodrigues, B. N.; Almeida, F. S. Guia de herbicidas. 6. ed. Londrina: Edição dos Autores, 2011. 697 p.

Rodrigues, B. N.; Almeida, F. S. Guia de Herbicidas. $5^{\text {a }}$ edição. Londrina, IAPAR, 2005.

Roman, E. S.; Beckie, H.; Vargas, L.; Hall, L.; Rizzardi, M.; Wolf, T. M. Como funcionam os herbicidas: da biologia à aplicação. Passo Fundo. Gráfica Editora Berthier, p. 152. 2005.

Santos, D. P.; Braga, R. R.; Guimarães, F. A. R.; Passos, A. B. R. J.; Silva, V. D.; Santos, J. B.; Nery, M. C. Determinação de espécies bioindicadoras de resíduos de herbicidas auxínicos. Revista Ceres, Viçosa, v. 60, p. 354362,2013 .

Santos, M. V.; Freitas, F. C. L.; Ferreira, F. A.; Viana, R. G.; Santos, L. D. T.; Fonseca, D.M. Eficácia e persistência no solo de herbicidas utilizados em pastagem. Planta Daninha, v. 24, p. 391-398, 2006.

Silva, A. A.; Vargas, L.; Ferreira, E. A. Herbicidas: comportamento no solo. Ed. Tópicos em manejo de plantas daninhas. Viçosa, MG: Universidade Federal de Viçosa, 2007. p. 189-248.

Silva, A. D.; Ferreira, F. A.; Ferreira, L. R. Biologia e controle de plantas daninhas. Viçosa, MG: Universidade Federal de Viçosa, 2005. CD-Rom.

Silva, A. M. Eficiência do uso de herbicidas sistêmicos em recuperação de pastagens. Cadernos de pós-graduação da FAZU, v. 2. 2011.

Silva, F. M. L.; Cavalieri, S. D.; São José, A. R.; Ulloa, S. M.; Velini, E. D. Atividade residual de 2, 4-D sobre a emergência de soja em solos com texturas distintas. Revista Brasileira de Herbicidas, v. 10, n. 1, p. 29-36, 2011.
Silva, V. M. Soja como bioindicador para o estudo do potencial de lixiviação do 2,4-D em Latossolo Vermelho em chuva simulada. Dissertação (Mestrado) Universidade Federal de Mato Grosso, Faculdade de Agronomia e Medicina Veterinária. Programa de PósGraduação em Agricultura Tropical. Cuiabá, 2017.

Timossi, P. C.; Silva, W. S.; Lima, S. F.; Alves, V. F.; Almeida, D. P. Efeito residual de herbicidas na cultura do crambe em sucessão. Revista Brasileira de Herbicidas, v. 12, p. 277-284, 2013.

Wax, L. M.; Knuth, L. A.; Slife, F. W. Response of soybeans to 2,4- D, dicamba and picloram. Weed Science, v. 17 , p. $388-393,1969$. 